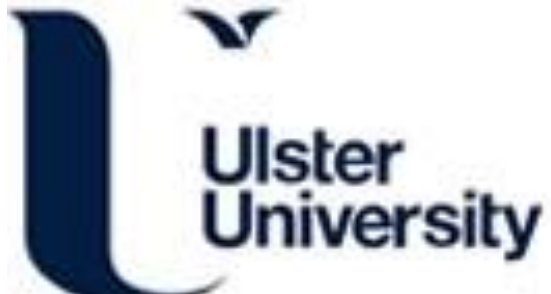

\section{A Thermodynamic Micellization and Hemolysis Evaluation of Polysorbate Surfactants in Combination with Short-Chain Alcohols}

Salarpour, S., Rajaee, M., Mohajeri, E., Hobab, M., Ohadi, M., Banat, I. M., \& Dehghannoudeh, G. (2021). A Thermodynamic Micellization and Hemolysis Evaluation of Polysorbate Surfactants in Combination with ShortChain Alcohols. Journal of Cluster Science. https://doi.org/10.1007/s10876-021-02012-9

Link to publication record in Ulster University Research Portal

Published in:

Journal of Cluster Science

Publication Status:

Published (in print/issue): 08/02/2021

DOI:

https://doi.org/10.1007/s10876-021-02012-9

\section{Document Version}

Author Accepted version

\section{General rights}

Copyright for the publications made accessible via Ulster University's Research Portal is retained by the author(s) and / or other copyright owners and it is a condition of accessing these publications that users recognise and abide by the legal requirements associated with these rights.

\section{Take down policy}

The Research Portal is Ulster University's institutional repository that provides access to Ulster's research outputs. Every effort has been made to ensure that content in the Research Portal does not infringe any person's rights, or applicable UK laws. If you discover content in the Research Portal that you believe breaches copyright or violates any law, please contact pure-support@ulster.ac.uk. 
2 A thermodynamic micellization and hemolysis evaluation of polysorbate surfactants in 3 combination with short-chain alcohols

4

5 Soodeh Salarpour ${ }^{\text {a, b}}$, Majid Rajaee ${ }^{\text {a, b* }}$, Ehsan Mohajeri ${ }^{\text {a, b }}$, Maryam Hobab ${ }^{\text {a }}$, Mandana Ohadi ${ }^{\text {a }}$, Ibrahim M.

6 Banat $^{\mathrm{c}}$, Gholamreza Dehghannoudeh ${ }^{\mathrm{a}, \mathrm{b}^{* * *}}$

7 a Pharmaceutics Research Center, Institute of Neuropharmacology, Kerman University of Medical Sciences,

8 Kerman, Iran

$9{ }^{b}$ Department of Pharmaceutics, Faculty of Pharmacy, Kerman University of Medical Sciences, Kerman, Iran $10{ }^{c}$ School of Biomedical Sciences, Faculty of Life \& Health Sciences, University of Ulster, Coleraine BT52

11 1SA, Northern Ireland, UK

12 Corresponding author:

$13{ }^{*}$ Majid Rajaee, Pharmaceutics Research Center, Institute of Neuropharmacology, Kerman University of 14 Medical Sciences, Kerman,Iran.Email:dr.rajaee@ssu.ac.ir

$15{ }^{* *}$ Gholamreza Dehghannoudeh, Pharmaceutics Research Center, Institute of Neuropharmacology, Kerman 16 University of Medical Sciences, Kerman, Iran.Email: ghr_dehghan@kmu.ac.ir(G.Dehghan-Noudeh) 17 gholamreza.dehghannoudeh@utoronto.ca 
Abstract:

Surface active agents have been used in many pharmaceutical formulations for different purposes as

30

31

32

33 penetration enhancers. In this study, the penetration enhancement activity of four nonionic surfactants from polyoxyethylene sorbitan fatty acid esters alone and in combination with some short-chain alcohols on red blood cells were investigated. Hemolysis at different concentrations of each nonionic surfactant $(0.1,0.2,0.5$, 1, and 2\%) and ethanol, isopropyl alcohol, glycerol, and propylene glycol $(0.5,1,2,5$, and $10 \%$ w/v) were investigated. Critical micelle concentration (CMC) and micellization thermodynamic parameters of tween 80 in presence of ethanol and glycerol at different concentrations were determined. The influence of the ethanol and glycerol on nonionic surfactant micelle formation was evaluated by determining CMC and micellization thermodynamic parameters of tween 80 at different concentrations of alcohol-tween mixtures. The mixture of Tween 20 and glycerol have the lowest hemolytic activity while tween 80 -ethanol mixture has the highest hemolysis activity. The self-aggregation of surfactant monomers was affected by short-chain alcohols. The structure breaking ability of alcohol and their interactions with the hydrophilic-hydrophobic groups of surfactants might be the main factors for changing the micelle formation. The CMCs of tween 80 was incremented by increasing the concentration of alcohol. The results indicated that by adding and increasing short chain alcohols the CMCs increased also the CMCs were increasing through raising the temperature (while in the presents of surfactants alone the CMCs decreased by raising temperature).

Keywords: polysorbate surfactants, ethanol, isopropyl alcohol, glycerol, propylene glycol, hemolysis, thermodynamic 
53

54

55

56

57

58

59

60

61

62

63

64

65

66

67

68

69

\section{Introduction}

Penetration enhancers (PEs) are chemical substances widely used in topical and transdermal preparations to increase drug penetration to deeper layers of skin. Various kinds of PEs such as surfactants, alcohols, glycols, fatty acids, and urea, among others have been utilized in such topical formulations [1]. Alcohols in various concentrations have been reported as an efficient permeation enhancer in dermal and transdermal preparations. Ethanol and isopropyl alcohol (IPA) are the two most common short-chain alcohols utilized in topical products. Different mechanisms for the enhancement permeation effect have been suggested such as acting as a co-solvent or alteration of stratum corneum structure. Other excipients that have been used widely in topical formulations include glycols. Propylene glycol (PG) is the most commonly used as a PEs and cosolvent for poorly soluble drugs. Surfactants are amphiphilic compounds utilized in many therapeutic and cosmetic formulations in order to solubilize lipophilic ingredients. All kinds of surfactants such as anionic, cationic, non-ionic, zwitterion, and biosurfactants have been investigated as PEs with different mechanisms of action, among them the non-ionic surfactants possess the least toxicity and skin irritation [2].They have the potential to solubilize the stratum corneum lipids which enhances drug penetration to the inner layers of skin. Surfactants and alcohols abilities to solubilize the lipidic components of biological membranes could have some toxic effects on cells. Various models have been suggested for estimating membrane toxicity and the erythrocyte $(\mathrm{RBC})$ hemolysis model is one of them. The availability of blood, easy isolation of RBC, and the membrane similarities of RBC to other cells membrane are advantages of this model. Surfactants are known to produce supramolecular structures called micelles only when the concentration of surfactant is at or greater than the CMC. CMC is one of the most important physical parameters of surfactants and can be estimated through some physicochemical properties of surfactants such as interfacial tension, conductivity, viscosity [3, 4], osmotic pressure, density [5], polarity, specific heat, UV-Vis spectrophotometric method [6] refractive index [7], and solubilization power [8,9]. During the formation of micelles, the effects of different factors including surfactant structure, temperature, pressure, $\mathrm{pH}$, and additives on micellization can be 
represented by thermodynamics. Several investigations have been carried out on temperature and additives effects as these parameters significantly affect surfactants properties. Thermodynamic parameters of micellization include standard Gibbs free energy $\left(\Delta \mathrm{G}_{\mathrm{m}}^{\circ}\right)$, enthalpy $\left(\Delta \mathrm{H}_{\mathrm{m}}^{\circ}\right)$ and entropy $\left(\Delta \mathrm{S}_{\mathrm{m}}^{\circ}\right)$ and have been used to quantify the relative importance of hydrophobic interactions and surfactant-water contacts [10]. These parameters can be derived from Van't Hoff equation that describes the dependency of CMC on temperature. $\mathrm{CMC}$ of nonionic surfactants decreases by increasing the temperature up to $50^{\circ} \mathrm{C}$. Breaking hydrogen bonds between the water and hydrophilic chains of surfactants is the reason for the reduction of CMC a process that has been demonstrated in nonionic surfactants at increasing temperatures [11, 12]. Surfactants and alcohols are often used together as PEs and co-solvent in some formulations. Therefore, the effect of short-chain alcohols addition on the thermodynamic micellization parameters of nonionic surfactants has been considered by Ruiz and co-workers [13] and Glenn and co-workers [14] who evaluated the effect of ethylene glycol on micellization of tween surfactants $20,40,60$, and 80 . They reported that the structure breaking ability of ethylene glycol and its interaction with the hydrophilic groups of the surfactant were the main controlling factors in the micellization leading to increased micellization [13, 14]. In another study, it was shown by the addition of ethanol and ethylene glycol to anionic surfactant aqueous solution, the Gibbs free energy of micellization became less negative in comparison to treatments without any additives. The $\Delta \mathrm{S}_{\mathrm{m}}^{\circ}$ was larger than the $\Delta \mathrm{H}_{\mathrm{m}}^{\circ}$ in aqueous solution without any co-solvent while in the presence of cosolvent the enthalpic role predominates [15]. Since the polysorbates are used frequently in formulations and usually they are in combination with some alcohols, few studies appear in the literature on these mixtures. In this study, the simultaneous effects of some short-chain alcohols on erythrocyte lysis and the thermodynamics of micellization were investigated.

\section{Materials and methods}

\section{2-1-Material}

The surfactant Tween 20 (Polyoxyethylenesorbitan monolaurate), Tween 40 (Polyoxyethylenesorbitan monopalmitate), Tween 60 (Polyoxyethylenesorbitan monoestearate), 80 (Polyoxyethylenesorbitan 
103 monooleate), citric acid (analytical grade), sodium chloride, potassium ferricyanide, potassium cyanide, PG

104 (analytical grade), IPA (analytical grade) and potassium dihydrogen phosphate were obtained from Merck, 105 Germany. Ethanol 96\% and Glycerol were obtained from Sepidaj, Iran. Doubly distilled and deionized water 106 was used to prepare all fresh solutions.

107 2-2- Hemolysis evaluation

108 2-2-1-Preparation of RBC suspension

109 Human blood was collected from a healthy volunteer in a heparinized tube. After centrifugation (Spectrafuge $110161 \mathrm{M}$, England) at $3000 \mathrm{rpm}$ for $10 \mathrm{~min}$ RBC were separated, washed three times with McIlvaine's buffer $111\left(0.2 \mathrm{M} \mathrm{Na}_{2} \mathrm{HPO}_{4}, 0.1 \mathrm{M}\right.$ citric acid adjusted to $\left.\mathrm{pH} 7.0\right)$ and erythrocytes re suspended in the same buffer to 112 achieve a suspension with $12 \%$ hematocrit.

113 2-2-2-Assessment of hemolysis

114 Mixtures of different ratios of each polysorbate (Tweens) and alcohols $(200 \mu 1)$ were added to equal volume 115 of $\mathrm{RBC}$ suspension and incubated at 25 and $37^{\circ} \mathrm{C}$ for 15 and $30 \mathrm{~min}$. After incubation intervals, the mixtures 116 were centrifuged at $3000 \mathrm{rpm}$ for $35 \mathrm{~s}$ and $200 \mu \mathrm{l}$ of supernatants were added to $3 \mathrm{ml}$ of Drabkin's reagent 117 (200mg potassium ferricyanide, 50mg of potassium cyanide, $1 \mathrm{~g}$ of sodium bicarbonate, and $0.1 \%$ nonionic 118 detergent in 1 liter of water). The absorbance of the samples at 540nm was read by a Synergy 2 microplate 119 ELISA reader (BioTek Inc., Winooski, USA). Positive control included $200 \mu$ of non-centrifuged erythrocyte 120 suspension and $200 \mu \mathrm{l}$ of McIlvaine's buffer which was mixed with 3ml Drabkin's reagent in which the whole 121 RBCs were lysed. Negative control was prepared by a mixture of $200 \mu 1$ erythrocyte and $200 \mu 1$ buffer then 122 centrifuged for $35 \mathrm{~s}$ and $200 \mu \mathrm{l}$ of supernatant was mixed with $3 \mathrm{ml}$ Drabkin's reagent. The hemolysis 123 percentage was calculated using the following equation:

124 Equation 1

$\%$ Hemolysis $=\left[\left(\mathrm{Abs}_{\mathrm{s}}-\mathrm{Abs}_{\text {neg }}\right) /\left(\mathrm{Abs}_{\text {pos }}-\mathrm{Abs}_{\text {neg }}\right)\right]^{* 100}$ 
In this equation Abss is the UV absorption of the sample and Absneg and Abspos are UV absorption of negative and positive control respectively. All experiments were carried out triple times and every samples freshly prepared [4].

2-3- Critical micelle concentration and thermodynamic studies:

131 The surface tension of solutions at various concentrations and temperatures were determined by Krüss 132 tensiometer K100, Germany with Wilhelmy platinum plate at constant conditions. The CMC was taken from 133 the breakpoint in the plot of surface tension vs logarithms of concentration values. In order to ensure 134 constancy of result the surface tensions of deionized water were periodically examined. The thermodynamic 135 of micellization was evaluated using CMC results obtained from experiments.

\section{3. Results}

\section{3-1- Hemolytic activity measurement}

Hemolytic activity of tweens (20, 40, 60, and 80) and alcohols (ethanol, isopropyl alcohol, PG, and glycerol) at two temperatures and two incubation times are shown in table 1 and 2.

Table 1: Hemolysis percentage of tween 20,40,60, and 80 at two temperatures and incubation times $(\mathrm{n}=3)$

\begin{tabular}{|c|c|c|c|c|c|c|c|c|c|c|c|c|c|c|c|c|}
\hline \multirow{2}{*}{$\begin{array}{c}\text { Conc } \\
\%\end{array}$} & \multicolumn{8}{|c|}{$25^{\circ} \mathrm{C}, 15 \mathrm{~min}$} & \multicolumn{8}{|c|}{$37^{\circ} \mathrm{C}, 15 \mathrm{~min}$} \\
\hline & $\begin{array}{c}\text { tween } \\
20\end{array}$ & SD & $\begin{array}{c}\text { tween } \\
40\end{array}$ & SD & $\begin{array}{c}\text { tween } \\
60\end{array}$ & SD & $\begin{array}{c}\text { tween } \\
80\end{array}$ & SD & $\begin{array}{c}\text { tween } \\
20\end{array}$ & SD & $\begin{array}{c}\text { tween } \\
40\end{array}$ & SD & $\begin{array}{c}\text { tween } \\
60\end{array}$ & SD & $\begin{array}{c}\text { tween } \\
80\end{array}$ & SD \\
\hline 0.1 & 10 & 0.3 & 8 & 0.2 & 3 & 0.1 & 12 & 0.4 & 15 & 0.5 & 10 & 0.2 & 5 & 0.2 & 14 & 0.3 \\
\hline 0.2 & 15 & 0.7 & 11 & 0.5 & 7 & 0.1 & 16 & 0.4 & 19 & 0.9 & 12 & 0.2 & 11 & 0.3 & 18 & 0.3 \\
\hline 0.5 & 25 & 1.1 & 22 & 1.0 & 12 & 0.6 & 24 & 0.9 & 28 & 1.8 & 25 & 1.1 & 18 & 0.9 & 26 & 1.5 \\
\hline 1 & 35 & 1.2 & 32 & 1.1 & 22 & 1.2 & 36 & 1.9 & 39 & 2.1 & 34 & 1.0 & 30 & 1.0 & 37 & 1.6 \\
\hline 2 & 45 & 1.5 & 39 & 1.8 & 27 & 1.9 & 77 & 2.1 & 47 & 1.1 & 40 & 2.1 & 37 & 1.8 & 40 & 2.2 \\
\hline 5 & 69 & 2.1 & 93 & 4.3 & 87 & 2.8 & 94 & 3.9 & 89 & 3.3 & 100 & 4.2 & 100 & 2.9 & 100 & 4.9 \\
\hline $\begin{array}{c}\text { Conc } \\
\%\end{array}$ & \multicolumn{8}{|c|}{$25^{\circ} \mathrm{C}, 30 \mathrm{~min}$} & \multicolumn{8}{|c|}{$37^{\circ} \mathrm{C}, 30 \mathrm{~min}$} \\
\hline 0.1 & 12.5 & 0.7 & 9.3 & 0.2 & 5.3 & 0.1 & 13.2 & 0.3 & 16.3 & 1.1 & 9 & 0.2 & 6 & 0.1 & 15 & 0.5 \\
\hline 0.2 & 17.3 & 0.6 & 12.4 & 0.3 & 9.2 & 0.1 & 17.4 & 0.2 & 20.01 & 1.0 & 10 & 0.3 & 10 & 0.6 & 20 & 1.0 \\
\hline 0.5 & 27.9 & 1.0 & 22.4 & 1.2 & 12.4 & 0.6 & 25.2 & 1.0 & 28.4 & 1.8 & 21 & 1.1 & 22 & 1.2 & 27 & 1.0 \\
\hline 1 & 37.8 & 1.7 & 39.9 & 1.6 & 24.2 & 1.5 & 38 & 1.4 & 40.2 & 2.3 & 31 & 2.1 & 33 & 1.5 & 38 & 2.1 \\
\hline 2 & 55.2 & 1.9 & 49.4 & 2.2 & 29.4 & 1.4 & 81.3 & 3.5 & 45 & 2.1 & 38 & 1.8 & 39 & 1.3 & 41 & 2.3 \\
\hline 5 & 79 & 2.7 & 95 & 3.8 & 90 & 4.3 & 97 & 3.3 & 100 & 3.8 & 100 & 3.1 & 100 & 3.3 & 100 & 4.1 \\
\hline
\end{tabular}


Table 2: Hemolysis percentage of ethanol, IPA, PG, and glycerol in two temperatures and incubation times

\begin{tabular}{|c|c|c|c|c|c|c|c|c|c|c|c|c|c|c|c|c|}
\hline \multirow{2}{*}{$\begin{array}{c}\text { Conc } \\
\%\end{array}$} & \multicolumn{8}{|c|}{$25^{\circ} \mathrm{C}, 15 \mathrm{~min}$} & \multicolumn{8}{|c|}{$37^{\circ} \mathrm{C}, 15 \mathrm{~min}$} \\
\hline & Ethanol & SD & IPA & SD & PG & SD & GLY & SD & Ethanol & SD & IPA & SD & PG & SD & GLY & SD \\
\hline 0.5 & 1.2 & 0.1 & 3.1 & 0.1 & 2.3 & 0.1 & 1.1 & 0.1 & 2.28 & 0.1 & 4.34 & 0.1 & 3 & 0.1 & 2.9 & 0.1 \\
\hline 1 & 3.7 & 0.1 & 5.4 & 0.1 & 3.5 & 0.2 & 4.2 & 0.2 & 7.03 & 0.2 & 7.56 & 0.1 & 4 & 0.1 & 6 & 0.2 \\
\hline 2 & 7.5 & 0.3 & 9.5 & 0.2 & 6.3 & 0.2 & 6.2 & 0.2 & 12 & 0.6 & 13.3 & 0.7 & 8.5 & 0.2 & 8 & 0.2 \\
\hline 5 & 12.4 & 0.8 & 16.1 & 0.6 & 9.2 & 0.5 & 10.3 & 0.5 & 21 & 1.2 & 22.54 & 1.6 & 14 & 0.7 & 11.1 & 0.6 \\
\hline 10 & 27.1 & 1.7 & 33.2 & 1.8 & 18.3 & 0.9 & 15.1 & 0.7 & 42 & 2.2 & 46.48 & 2.0 & 18 & 0.8 & 17 & 0.9 \\
\hline $\begin{array}{c}\text { Conc } \\
\%\end{array}$ & \multicolumn{8}{|c|}{$25^{\circ} \mathrm{C}, 30 \mathrm{~min}$} & \multicolumn{8}{|c|}{$37^{\circ} \mathrm{C}, 30 \mathrm{~min}$} \\
\hline 0.5 & 2.4 & 0.1 & 4.34 & 0.1 & 3.7 & 0.1 & 2.5 & 0.1 & 1.92 & 0.1 & 3.72 & 0.1 & 4.2 & 0.2 & 3.05 & 0.1 \\
\hline 1 & 4.44 & 0.1 & 7.56 & 0.2 & 4.9 & 0.1 & 5.6 & 0.2 & 5.92 & 0.1 & 7 & 0.2 & 5.4 & 0.2 & 6.15 & 0.1 \\
\hline 2 & 9 & 0.3 & 13.3 & 0.2 & 7.7 & 0.2 & 7.6 & 0.3 & 12 & 0.3 & 14 & 0.2 & 8.2 & 0.3 & 8.15 & 0.5 \\
\hline 5 & 14.88 & 0.6 & 22.54 & 0.9 & 10.6 & 0.4 & 11.7 & 0.5 & 21 & 1.1 & 23 & 0.9 & 11.1 & 0.6 & 12.25 & 0.5 \\
\hline 10 & 32.52 & 1.4 & 46.48 & 1.1 & 19.7 & 0.9 & 16.5 & 0.8 & 31 & 1.5 & 36 & 1.4 & 20.2 & 1.1 & 17.05 & 0.9 \\
\hline
\end{tabular}

149 Hemolytic activity of tweens in combination with each alcohol are shown in figures 1-3.

a)

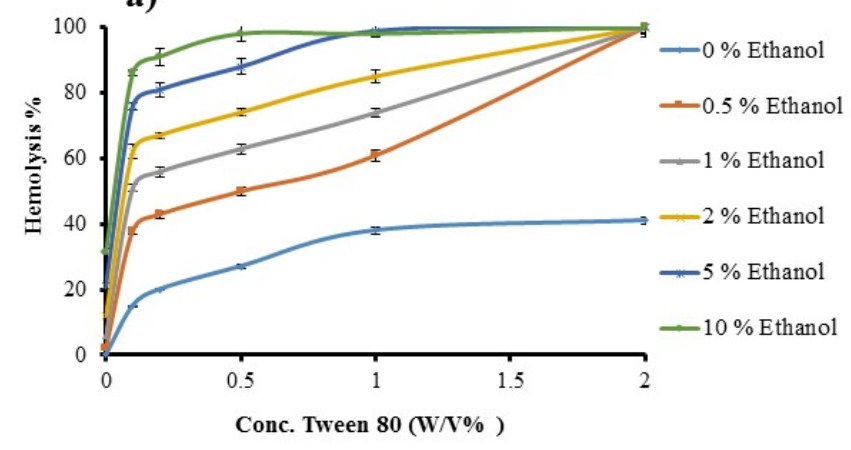

c)

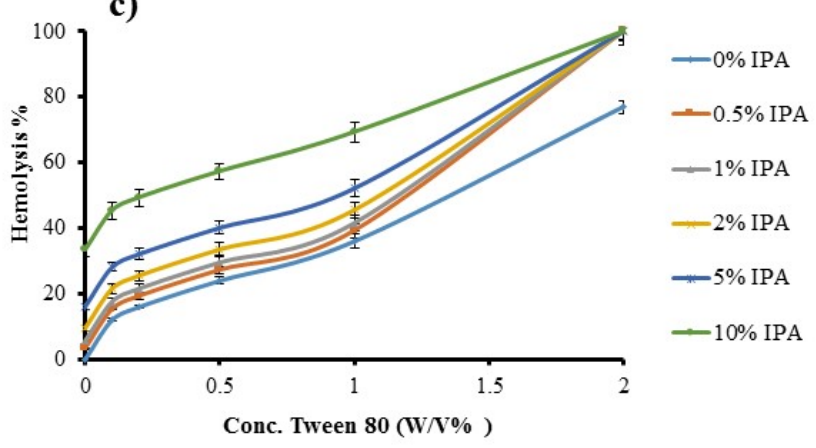

b)
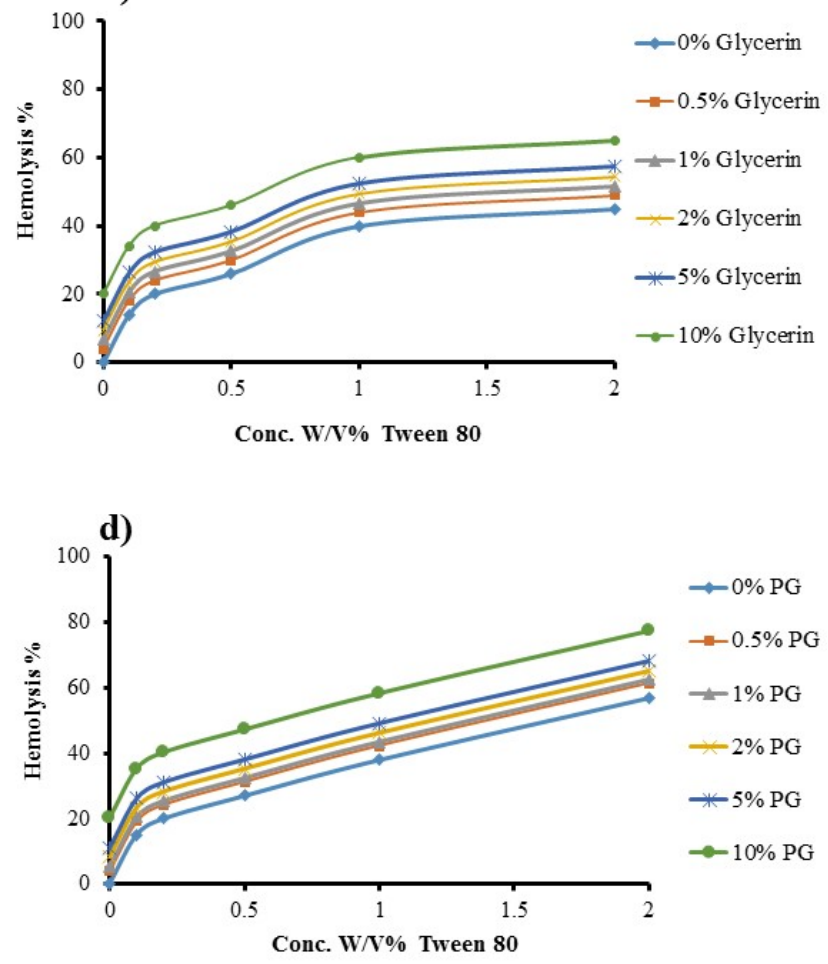

150

Figure 1: hemolysis activity of tween 80 combination with different alcohols at various concentrations: a) ethanol, b) glycerol, c) IPA and, d) PG 

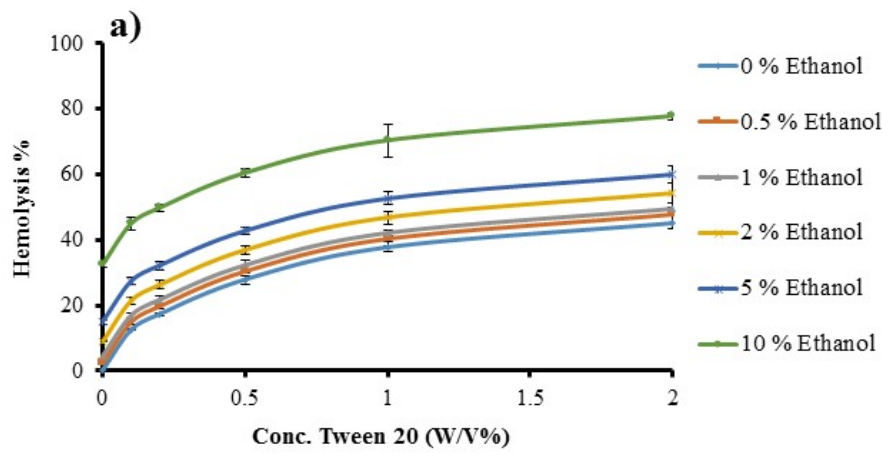

c)
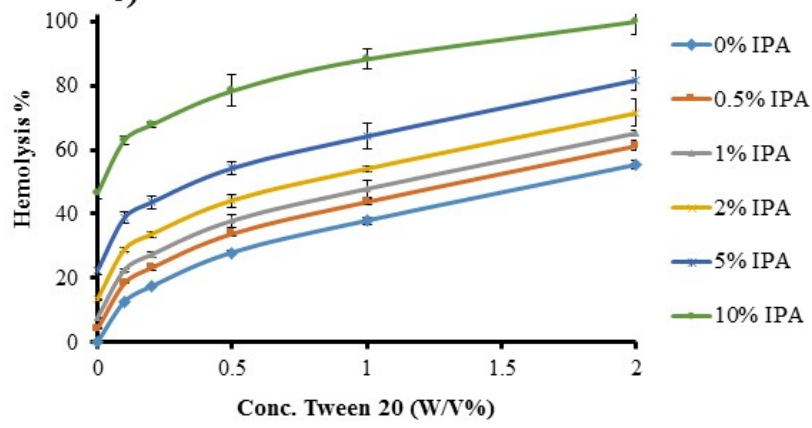

b)

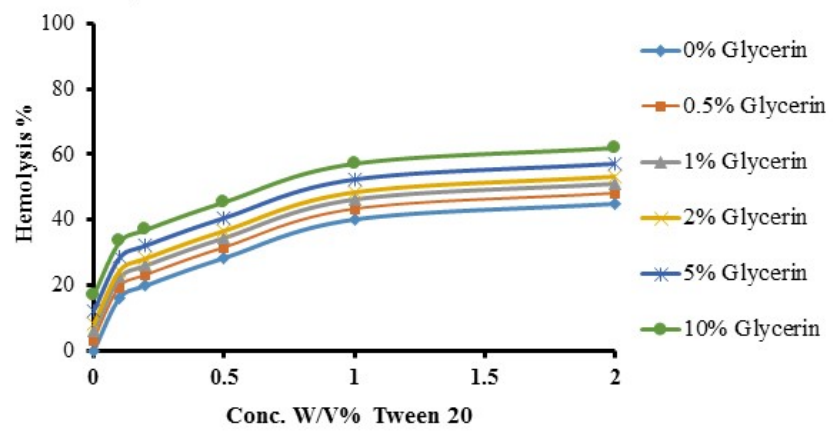

d)

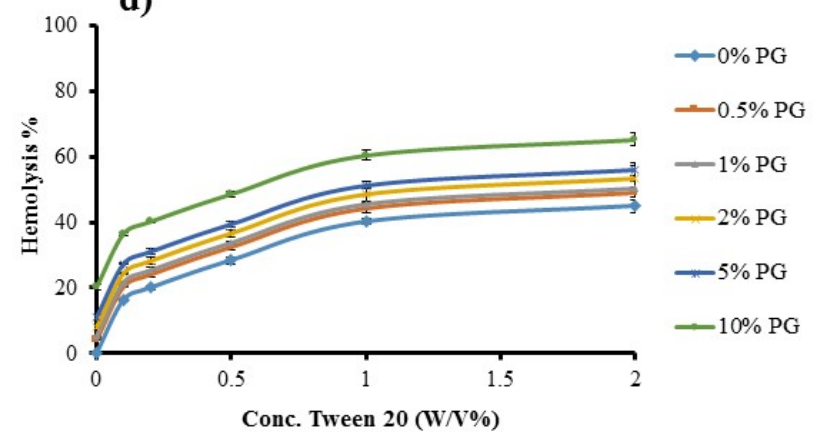

156 Figure 2: hemolysis activity of tween 20 combination with different alcohols at various concentrations: a) 157 ethanol, b) glycerol, c) IPA and, d) PG
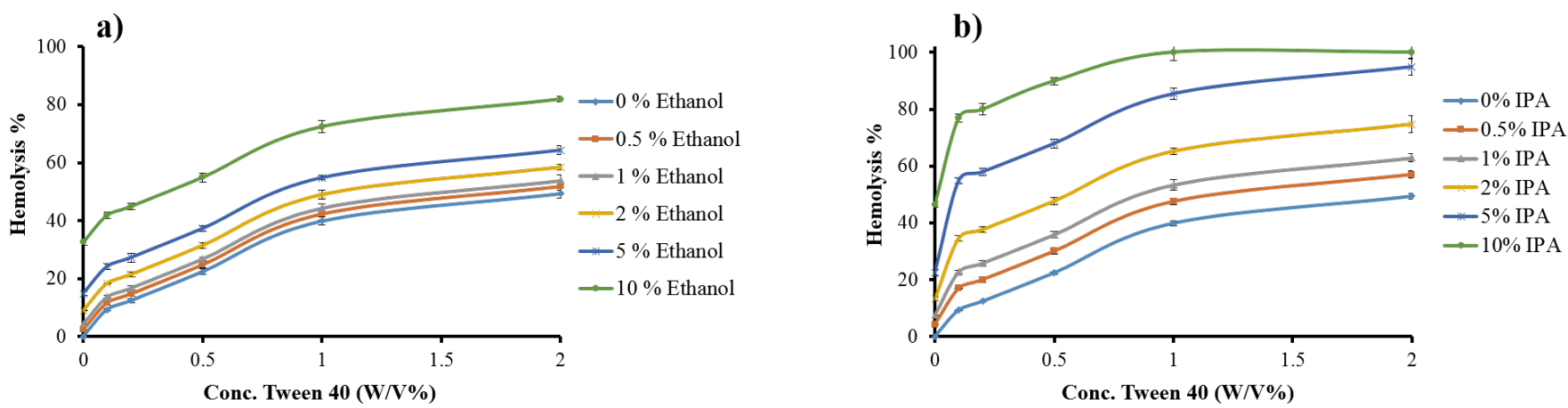

c)

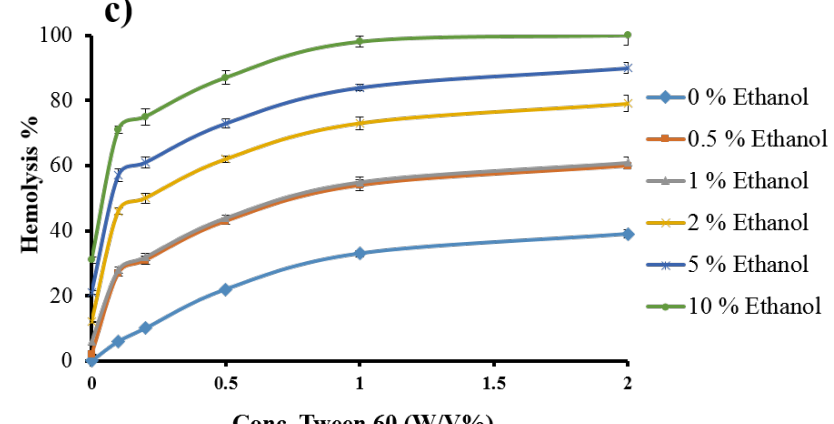

Conc. Tween $60(\mathrm{~W} / \mathrm{V} \%)$ d)

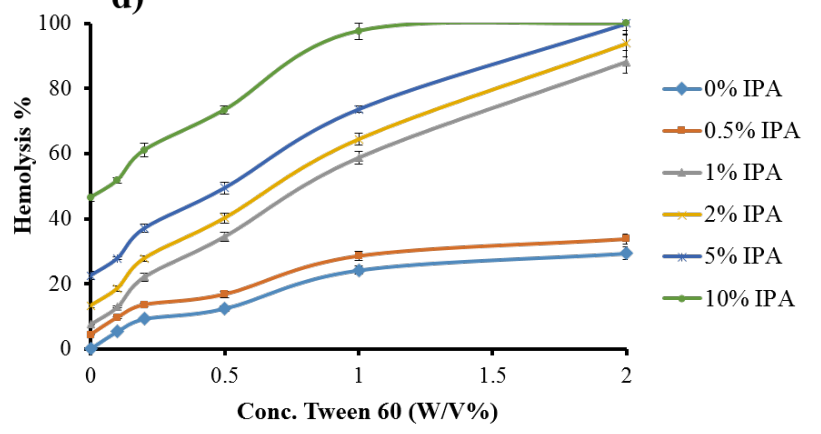

Figure 3: hemolysis activity of tweens 40, 60 combination with different alcohols at various concentrations: a) ethanol, b) glycerol, c) IPA and, d) PG 
3.2. Critical micelle concentration and thermodynamic study:

162

163 Thermodynamic study of nonionic surfactants was determined based on CMC to investigate the effect of

164 alcohols on it. The surface tension $(\gamma)$ of surfactants were measured at different concentrations and 165 temperatures. The CMC values were calculated from the surface tension versus surfactant logarithmic 166 concentration plot. The concentration which was the intersection point of the two linear portions of the plots 167 was reported as CMC point. CMC data of Tween 80 in combination with different concentrations of glycerol 168 and ethanol at different temperatures are listed in table 3.

169

176 In order to estimate the thermodynamic parameters of micellization, the temperature dependence of the 177 surfactants CMC could be used. The standard Gibbs free energy of micelle formation per mole of surfactant 178 monomer $\left(\Delta \mathrm{G}^{\circ} \mathrm{m}\right)$ was determined according to the mass action model which related to the $\mathrm{CMC}$ by the 179 following equation 2 :
Table 3: CMC of tween 80 in various ethanol and glycerol concentrations in aqueous solution at different temperatures

\begin{tabular}{cllll}
\hline \multirow{2}{*}{ Additive Concentration \% } & \multicolumn{3}{c}{ CMC values (mmol/l) } \\
\cline { 3 - 5 } & & $293 \mathrm{~K}$ & $308 \mathrm{~K}$ & $323 \mathrm{~K}$ \\
\hline \multirow{3}{*}{ Ethanol } & 0 & 0.013 & 0.011 & 0.008 \\
& 1 & 0.014 & 0.014 & 0.014 \\
& 10 & 0.016 & 0.017 & 0.019 \\
\hline \multirow{3}{*}{ glycerol } & 0 & 0.013 & 0.011 & 0.008 \\
& 1 & 0.013 & 0.013 & 0.014 \\
& 10 & 0.014 & 0.015 & 0.016
\end{tabular}


Equation 2

$$
\Delta G_{\text {mic }}^{0}=R T \ln X_{C M C}
$$

183

184 where XCMC is the surfactant mole fraction in CMC point. By putting the Gibbs-Helmholtz equation (Eq. 3)

185 in equation 2 enthalpy of micellization could be calculated as follows.

186 Equation 3

$$
\left(\frac{\partial\left(\frac{G}{T}\right)}{\partial T}\right)_{p}=-\frac{H}{T^{2}}
$$

188 Equation 4

189

\section{9}

191 obtain from above equations.

192 Equation 5

193

$\Delta S_{\text {mic }}^{0}=\frac{\Delta H_{\text {mic }}^{0}-\Delta G_{\text {mic }}^{0}}{T}$

194 195

$$
\Delta \mathrm{G}_{\mathrm{trans}}^{0}=\left(\Delta \mathrm{G}_{\mathrm{mic}}^{0}\right)_{\mathrm{additive}+\mathrm{H}_{2} \mathrm{O}}-\left(\Delta \mathrm{G}_{\mathrm{mic}}^{0}\right)_{\mathrm{H}_{2} \mathrm{O}}
$$


Table 4: Micellization thermodynamics of tween 80 in various ethanol concentrations in water mixture

\begin{tabular}{|c|c|c|c|c|c|}
\hline \multirow{2}{*}{ Ethanol (\%) } & $\mathrm{T}(\mathrm{K})$ & $\begin{array}{c}\Delta G_{\text {mic }}^{0} \\
\left(\mathrm{kJmol}^{-1}\right)\end{array}$ & $\begin{array}{c}\Delta H_{\text {mic }}^{0} \\
\left(\mathrm{kJmol}^{-1}\right)\end{array}$ & $\begin{array}{c}\mathrm{T} \Delta S_{\text {mic }}^{0} \\
\left(\mathrm{kJmol}^{-1}\right)\end{array}$ & $\begin{array}{c}\Delta G_{\text {trans }}^{0} \\
\left(\mathrm{kJmol}^{-1}\right)\end{array}$ \\
\hline \multirow{3}{*}{0} & 293 & -37.25 & 10.76 & 48.01 & - \\
\cline { 2 - 6 } & 308 & -39.52 & 11.89 & 51.42 & - \\
\cline { 2 - 6 } & 323 & -42.28 & 13.08 & 55.36 & - \\
\hline \multirow{3}{*}{1} & 293 & -37.08 & -0.85 & 36.24 & 0.16 \\
\cline { 2 - 6 } & 308 & -38.93 & -0.94 & 37.99 & 0.59 \\
\cline { 2 - 6 } & 323 & -40.79 & -1.03 & 39.76 & 1.49 \\
\hline \multirow{3}{*}{10} & 293 & -36.60 & -4.69 & 31.90 & 0.65 \\
\cline { 2 - 6 } & 308 & -38.20 & -5.18 & 33.02 & 1.32 \\
\cline { 2 - 6 } & 323 & -39.81 & -5.70 & 34.11 & 2.47 \\
\hline
\end{tabular}

204 Table 5: Micellization thermodynamics of tween 80 in various glycerol concentrations in water mixture

\begin{tabular}{|c|c|c|c|c|c|}
\hline $\begin{array}{c}\text { Glycerol } \\
(\%)\end{array}$ & $\mathrm{T}(\mathrm{K})$ & $\begin{array}{c}\Delta G_{\text {mic }}^{0} \\
\left(\mathrm{kJmol}^{-1}\right)\end{array}$ & $\begin{array}{c}\Delta H_{\text {mic }}^{0} \\
\left(\mathrm{kJmol}^{-1}\right)\end{array}$ & $\begin{array}{c}\mathrm{T} \Delta S_{\text {mic }}^{0} \\
\left(\mathrm{kJmol}^{-1}\right)\end{array}$ & $\begin{array}{c}\Delta G_{\text {trans }}^{0} \\
\left(\mathrm{kJmol}^{-1}\right)\end{array}$ \\
\hline \multirow{3}{*}{0} & 293 & -37.25 & 10.76 & 48.01 & - \\
\cline { 2 - 6 } & 308 & -39.52 & 11.89 & 51.42 & - \\
\cline { 2 - 6 } & 323 & -42.28 & 13.08 & 55.36 & - \\
\hline \multirow{3}{*}{1} & 293 & -37.16 & -0.87 & 36.29 & 0.09 \\
\cline { 2 - 6 } & 308 & -39.04 & -0.97 & 38.07 & 0.49 \\
\cline { 2 - 6 } & 323 & -40.87 & -1.06 & 39.80 & 1.41 \\
\hline \multirow{3}{*}{10} & 293 & -36.77 & -2.84 & 33.93 & 0.48 \\
\cline { 2 - 6 } & 308 & -36.65 & -3.13 & 33.52 & 2.87 \\
\cline { 2 - 6 } & 323 & -36.48 & -3.45 & 33.03 & 5.80 \\
\hline
\end{tabular}

206 In order to evaluate the enthalpy-entropy compensation phenomenon, micellization enthalpy of tween 80 207 were plotted versus $\mathrm{T} \Delta \mathrm{S}_{\text {mic }}^{0}$, these data were obtained from micelle formation at different concentrations of 208 ethanol and glycerol mixtures, $a$ and $b$ respected in Fig. 4. The enthalpy and the entropy change had a linear 209 correlation that could be described by the equation 6.

$210 \quad$ Equation 7

$$
\Delta H_{\text {mic }}^{0}=\Delta H_{0, m i c}^{0}+\beta \mathrm{T} \Delta S_{\text {mic }}^{0}
$$



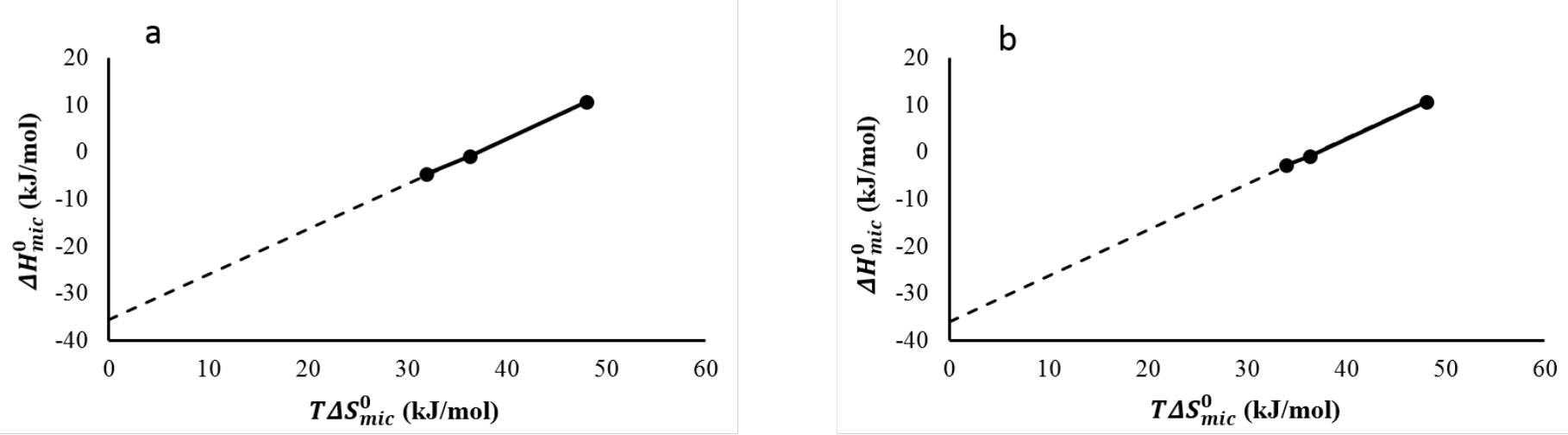

212

213

214

215

216

217

218

219

220

221

222

223

224

225

226

227

228

229

230

231

232

233

Figure 4: $\Delta \mathrm{H}_{\operatorname{mix}}^{0}$ versus $T \Delta \mathrm{S}_{\mathrm{mic}}^{0}$ at $293 \mathrm{~K}$ for the micellization of tween 80 in different ethanol / glycerol-water mixtures (a: ethanol and b: glycerol)

\section{Discussion:}

Various components have been used in pharmaceutical formulations to improve the penetration of active ingredients to the inner layers of skin. Surfactants and alcohols are two main groups of PEs that are widely used in topical preparations as a solubilizer and penetration enhancer on stratum corneum by reversibly altering the bilayer cell membranes may potentially be toxic to the cells. In this study, we aimed to determine the toxicity of these materials on cells using the erythrocyte model technique. In this technique, we evaluated the extent of RBC hemolysis after exposure to different concentrations of surfactants and alcohol at two temperatures and durations. Surfactants and alcohols can lyse erythrocytes by enhancing penetration of some compounds through the cell membrane resulting in increased osmotic pressure inside cells which destroys the RBC [16, 17]. The degree of hemolysis depends on surfactants and alcohol (PEs) concentrations, temperature, and contact time with erythrocytes. In this study, we used different concentrations of surfactants $(0-5 \% \mathrm{w} / \mathrm{v})$ and alcohols $(0-10 \% \mathrm{w} / \mathrm{v})$ at two temperatures $\left(25\right.$ and $\left.37^{\circ} \mathrm{C}\right)$ and two exposure durations of 15 and 30 minutes. By increasing the concentration of surfactants and alcohol more hemolytic activity was observed. Similar results were reported by previous researches more hemolysis occurs when higher concentrations of PEs molecules are in contact with RBCs' cell membrane. Cell membranes consist of 
bilayers that have liquid and jelly characteristic. These structures contain phospholipids which convert to the

jelly mode when temperature decreases below $37 \mathrm{oC}$. This conversion of phospholipids to jelly form results in

a more stable cell membrane which increases resistance against cell lysis [18]. Therefore, the degree of hemolysis in samples at $37^{\circ} \mathrm{C}$ was more than that at $25^{\circ} \mathrm{C}$ except for glycerol and PG.

Increasing the exposure time and prolonging contact duration of PEs with the erythrocytes led to increased hemolytic effects which have also been reported by other researches [19]. When using short-chain alcoholic compounds while the number of hydroxyl groups increases, the hydrophilicity increases so their penetration into the cell membrane decreases. When alcohols have the same number of hydroxyl groups, other factors that may affect their hydrophilicity can cause differences in the levels of hemolytic activities. When alcoholic agents have higher molecular weights the compound consequently have higher melting point and accordingly lower hemolysis levels. When alcohol and tweens are used together, the combination of ethanol (a shortchain alcohol) and tween results in higher levels of hemolysis while when a mixture of glycerol (higher chain alcohol) and tween is used less hemolysis effects are observed. According to table 3, the CMC values of tween 80 decreased when the temperature increased which again is consistent with previous studies [11]. This occurs because of higher molecular movements at elevated temperatures as the chance of hydrogen bond formation decreased. The increase in temperature causes a reduction in hydration of the hydrophilic oxyethylene groups in tweens that is favorable for micellization. The hydrophilicity of the surfactant molecules was decreased by the reduction of hydrogen bonding so micelles formed at lower concentration. When the temperature increases further, the movement of water and surfactant molecules increases, which cause an increase $\mathrm{CMC}$ value [12]. The $\mathrm{CMC}$ has been affected by the addition of ethanol and glycerol. Hydrophobic bonds have important role in micelle formation in surfactant mixtures. In nonionic surfactant mixtures, the molecules that form micelles compact closely so penetration of ethanol molecules into the micelles would decrease. Therefor low concentration of ethanol and glycerol would have little effect on the CMC but by increasing ethanol and glycerol concentration, hydrophobic interactions between the hydrophobic tails of surfactants were gradually reduced. As a whole, the addition higher of ethanol and 
glycerol concentration increase gradually the $\mathrm{CMC}$ of the mixture $[20,21]$. Increasing the temperature of the surfactant mixture in the presence of glycerol or ethanol makes the CMC go up which is opposite to that surfactant mixture with water. This CMC increasing is attributed to the disruption of the solvent structure at higher temperature $[13,14]$. The thermodynamic parameter has an important role in realizing the micellization process. The interpretation of these parameters is necessary to consider the effects of cosolvents and temperature on the CMC value [22]. According to the results, the free energy of micellization in surfactant mixtures alone and with additives (ethanol and glycerol) is negative and becomes less negative as the content of the additives in the solution increases. The enthalpy value of micellization indicates that it is an exothermic process and decreases with increasing ethanol and glycerol concentrations. In Micellization endothermic and exothermic processes are effective. As ethanol and glycerol added to the surfactant mixture breaking up the hydrophobically structured water surrounding the hydrocarbon chains is an exothermic effect while the endothermic effect due to the transfer of the hydrophobic groups from water to the aqueous cosolvent mixture and the exothermic process is dominant over the endothermic process. Entropy change if micelle formation is related to aggregation of surfactant molecules so its change is predictably negative. On the other hand, the hydrophobically structured water around the hydrophobic tail becomes free or destructured when micelles are formed. The entropy of micellization is a combination of the above two effects. Thus, with increasing content of co-solvent in the surfactant mixture, the entropy values decrease meanwhile the values of enthalpy become more negative. Therefore, at the higher co-solvent concentration enthalpy is the dominating factor in the forming micelles process as shown in tables 4 and 5 . In order to evaluate the effect of co-solvent on the micellization, the free energy of transfer ( $\Delta \mathrm{G}$ trans) could be used. The values of $\Delta \mathrm{G}_{\mathrm{trans}}$ is positive for all systems [23]. The $\Delta \mathrm{G}$ trans value increases with increasing concentration of co-solvent because the hydrophobic tails of the tween interact with the hydrophobic part of co-solvent and hydrophilic heads of tween interact with water that decreases the aggregation of surfactant monomers $[15$, 23]. In enthalpy-entropy compensation phenomenon, micellization is divided into "solvation" and "chemical" part [24]. From the slope of the enthalpy-entropy compensation plot, the solvation part of 
micellization can be obtained and the intercept of this plot indicates the chemical part of the micelle

285 formation [25]. As shown in Fig 4, compensation between the $T \Delta \mathrm{S}_{\text {mic }}^{0}$ and $\Delta \mathrm{H}_{\text {mic }}^{0}$ values is found in different 286 concentration of ethanol and glycerol which $\Delta H_{0 \text { mic }}^{0}$ is the intercept of $\Delta \mathrm{H}_{\text {mic }}^{0}$ against $\mathrm{T} \Delta \mathrm{S}_{\text {mic }}^{0}$ plot and its 287 slope is $\beta$. The $\Delta H_{0 \text { mic }}^{0}$ and $\beta$ for ethanol - water mixture were $-35.61 \mathrm{~kJ} \mathrm{~mol}^{-1}$ and 0.96 and for glycerol288 water mixture were $-36.05 \mathrm{~kJ} \mathrm{~mol}^{-1}$ and 0.97 respectively. In equation $7, \beta$ represent a quantitative 289 correlation of the enthalpy-entropy compensation. The negative value of $\Delta H_{0 \text { mic }}^{0}$ (the intrinsic enthalpic 290 gain) confirms that the micellization is desirable although the entropic gain is not exciting.

\section{5. Conclusion:}

292 Presence of four short chain alcohols with non ionic surfactants (Tweens) affected on the RBC lysis and 293 micellization properties. Different actions of lysis on RBCs were seen in alcohols and poly sorbates 294 combination such as higher lysis in mixture of short chain alcohol (ethanol) in comparison with higher chain 295 alcohol (glycerol). The thermodynamic study of these mixtures was shown alcohols reduced micellization 296 tendency in Tween 80 due to structure breaking ability of alcohols.

\section{Acknowledgments}

298 The authors would like to thank Kerman University of Medical Sciences (KMU) for facilitating research into 299 the conclusions of this study.

\section{Conflict of interest statement:}

The authors report no conflict of interest. 
[1] A.C. Williams, B.W. Barry, Advanced drug delivery reviews, 64 (2012) 128-137.

[2] A. Pandey, A. Mittal, N. Chauhan, S. Alam, J Mol Pharm Org Process Res, 2 (2014) 2-7.

[3] M. Bielawska, A. Chodzińska, B. Jańczuk, A. Zdziennicka, Colloids and Surfaces A: Physicochemical and Engineering Aspects, 424 (2013) 81-88.

[4] M. Ohadi, G. Dehghannoudeh, H. Forootanfar, M. Shakibaie, M. Rajaee, International journal of biological macromolecules, 112 (2018) 712-719.

[5] K. Szymczyk, A. Taraba, Journal of Thermal Analysis and Calorimetry, 126 (2016) 315-326.

[6] N.-M. Lee, B.-H. Lee, The Journal of Chemical Thermodynamics, 95 (2016) 15-20.

[7] C.H. Tan, Z.J. Huang, X.G. Huang, Analytical Biochemistry, 401 (2010) 144-147.

[8] M.E. Mahmood, D.A. Al-Koofee, Global J Sci Front Res Chem, 13 (2013) 1-8.

[9] K.S. Sharma, S.R. Patil, A.K. Rakshit, K. Glenn, M. Doiron, R.M. Palepu, P.A. Hassan, The Journal of Physical Chemistry B, 108 (2004) 12804-12812.

[10] S. Shimizu, P.A.R. Pires, W. Loh, O.A. El Seoud, Colloid and Polymer Science, 282 (2004) 1026-1032.

[11] E. Mohajeri, G.D. Noudeh, Journal of Chemistry, 9 (2012) 2268-2274.

[12] L.-J. Chen, S.-Y. Lin, C.-C. Huang, E.-M. Chen, Colloids and Surfaces A: Physicochemical and Engineering Aspects, 135 (1998) 175-181.

[13] C.C. Ruiz, J. Molina-Bolívar, J. Aguiar, G. MacIsaac, S. Moroze, R. Palepu, Colloid and Polymer Science, 281 (2003) 531-541.

[14] K.M. Glenn, S. Moroze, S.C. Bhattacharya, R.M. Palepu, Journal of dispersion Science and technology, 26 (2005) 79-86.

[15] H. Akbaş, C. Kartal, Colloid Journal, 68 (2006) 125-130.

[16] G. Noudeh, P. Khazaeli, E. Behravan, M.A. Afzadi, A. Dehghan-Noudeh, M. Hassani, African Journal of Biotechnology, 10 (2011) 9931-9938. 
337 [17] M. Manaargadoo-Catin, A. Ali-Cherif, J.-L. Pougnas, C. Perrin, Advances in colloid and interface 338 science, $228(2016) 1-16$.

339 [18] G.D. Noudeh, F. Sharififar, M. Khatib, E. Behravan, M.A. Afzadi, African journal of Biotechnology, 9 $340 \quad(2010)$

341 [19] G.D. Noudeh, P. Khazaeli, P. Rahmani, Int. J. Pharmacol, 4 (2008) 27-33.

342 [20] J.-B. Huang, M. Mao, B.-Y. Zhu, Colloids and Surfaces A: Physicochemical and Engineering Aspects, $343155(1999) 339-348$.

344 [21] N. Nishikido, Y. Moroi, H. Uehara, R. Matuura, Bulletin of the Chemical Society of Japan, 47 (1974) $345 \quad 2634-2638$.

346 [22] Z. Kan, M.A. Malik, S.A. Al-Thabaiti, A. Alsehri, F. Nabi, J. Electrochem. Sci, 12 (2017) 4528-4542.

347 [23] Y. He, L. Sun, D. Fang, C. Han, C. Liu, G. Luo, Colloid Journal, 76 (2014) 96-103.

348 [24] R. Lumry, S. Rajender, Biopolymers: Original Research on Biomolecules, 9 (1970) 1125-1227.

349 [25] H. Akbaş, Ç. Batıgöç, Colloid journal, 70 (2008) 127-133. 